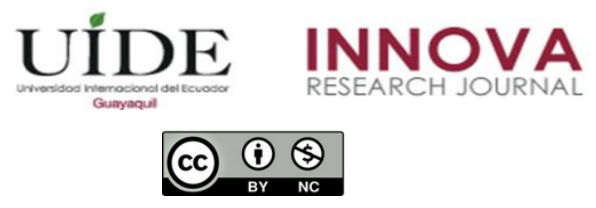

INNOVA Research Journal, ISSN 2477-9024

(Septiembre-Diciembre 2019). Vol. 4, No.3.2 pp. 63-79

DOI: https://doi.org/10.33890/innova.v4.n3.2.2019.1057

URL: http://revistas.uide.edu.ec/index.php/innova/index

Correo: innova@uide.edu.ec

\title{
Andragógica y Praxeología: Trialéctica para la transformación desde la comunicación universitaria
}

\section{Andragógica and Praxeología: Trialéctica for the transformation from the university communication}

Nanci Barrios Briceño

Universidad de Especialidades Espíritu Santo, Ecuador

Marieva Luchón Mogollón

Universidad Nacional Experimental Simón Rodríguez, Venezuela

María Eugenia Gómez Naranjo

Universidad Pedagógica Experimental Libertador, Venezuela

Autor para correspondencia: nbarrios@uees.edu.ec; marial89@hotmail.com;

profeupelmariae@hotmail.com

Fecha de recepción: 12 de julio de 2019 - Fecha de aceptación: 16 de octubre de 2019

\section{Resumen}

La presente investigación tuvo como propósito comprender cómo se vive en la educación universitaria la gestión andragógica, desde su praxis, examinando el discurso cotidiano de los informantes clave, con el fin último de construir una trama trialéctica para la transformación andragógica desde la praxeología apoyada en la comunicación. El estudio estuvo configurado en el paradigma pospositivista, enmarcado en un proceso metodológico fenomenológico hermenéutico. La información fue recabada aplicando como técnica una entrevista en profundidad a dos (2) facilitadores y un (1) participante de una Universidad pública en Venezuela, empleando como instrumento la grabadora. El tratamiento de los datos obtenidos se realizó en dos fases; la primera, fenomenológica aplicando las reducciones y la segunda a través del giro hermenéutico para lograr la interpretación. Todo ello permitió la Construcción de una Trama Trialéctica para la transformación andragógica fundamentada en la Praxeología, desde la cual se logre mirar a la educación universitaria desde una óptica de reflexión y acción de sus protagonistas, tomando como referentes tres aspectos fundamentales del individuo; lo humano, lo cognitivo y lo social.

Palabras claves: andragogía; praxeología; comunicación universitaria; trialéctica

\begin{abstract}
The present investigation had as purpose to understand how the andragogic management is lived in the university education, from its praxis, examining the daily speech of the key informants, with the last aim of constructing a trialétrica plot for the andragogic transformation from the supported praxeology in communication. The study was configured in the postpositivist paradigm, framed in a hermeneutical phenomenological methodological process. The information was collected applying as a technique an in-depth interview to two (2) facilitators and one (1) participant of a public University in Venezuela, using the recorder as an instrument. The treatment of the data obtained was carried out in two phases; the first, phenomenological applying the reductions and
\end{abstract}


the second through the hermeneutic turn to achieve the interpretation. All this allowed the construction of a Trialéctica plot for the andragogic transformation based on Praxeology, from which it is possible to look at the university education from a perspective of reflection and action of its protagonists, taking as referents three fundamental aspects of the individual; the human, the cognitive and the social.

Key words: andragogy; praxeology; university communication; trialéctica

\section{Introducción}

Para la educación en general y la superior, en particular, es importante propiciar la formación de futuros profesionales que potencien no solo el desarrollo y avance de la nación a través de su participación activa y abierta en diferentes escenarios vinculados al mundo del trabajo; sino también una educación que permita el perfeccionamiento de sí mismo como individuo, que promueva la autocrítica, la reflexión, la autorrealización, pues en la medida que se haga consciente de su importancia dentro de la sociedad podrá actuar en la prestación de servicios en pro del beneficio de ésta.

Ahora bien, la educación universitaria en las sociedades latinoamericanas es producto de profundos cambios culturales, sociales, políticos y económicos; cambios que han permitido contrastar los aspectos teóricos o el deber ser, con la realidad de cada contexto social, en la búsqueda del progreso de la misma. Por tal razón, se hace indiscutible el hecho de que las universidades cumplen un papel fundamental para el desarrollo de cada país; propiciando la formación del talento humano, la producción de conocimientos en ciencia y tecnología, la investigación, la actualización, lo que va a permitir que cada nación se beneficie de ese recurso humano que se formó en ellas.

En este sentido, Alcalá (2010) define la Andragogía como la ciencia y el arte que, siendo parte de la antropología y estando inmersa en la educación permanente, se desarrolla a través de una praxis fundamentada en los principios de participación y horizontalidad; sostiene que la praxis andragógica va a permitir que el adulto pueda lograr su autorrealización, por lo tanto, es necesario plantear en este discurso, que esa praxis se caracteriza por la toma de conciencia de las acciones ejecutadas por la persona adulta, en la que intervienen un conjunto de ideas, valores, actos y palabras orientadas al progreso del individuo y al cambio de su contexto con miras a un acrecentamiento del bienestar personal o social.

Ahora bien, tal planteamiento permite situarse en el centro de atención de la situación, al ver cómo se concibe el proceso educativo universitario y cómo es vista la educación desde la praxis andragógica, el cual propicia el encuentro entre el participante y el facilitador, en cómo conciben la formación desde esa perspectiva óntica que permite vislumbrar luego el hecho ontológico, como una herramienta reflexiva en la construcción del aprendizaje de ambos actores, donde la experiencia es la esencia que se encuentra implícita en este hecho.

Por otra parte, se debe reconocer la relevancia que tiene el hecho de que los actores involucrados directamente en esa praxis son el facilitador y el participante, y que ambos como adultos deben estar conscientes de que la didáctica andragógica requiere de un proceso de acción - reflexión - acción; de ellos, que permita romper los dogmas de la educación tradicional, 
propiciando un quiebre entre la pedagogía que aún existe en la universidad, donde autoridad versus poder son elementos dominantes; y la dinámica andragógica que debe darse en la misma, en la que la autoridad no debe medirse entre ellos, por el contrario la misma debe estar representada por el liderazgo, que se propicia poniendo en práctica los principios de horizontalidad y participación que rigen a la gestión andragógica.

Para ello, se deben considerar los postulados de la praxeología, definida por St-Arnaud y L'hotellier (1992) como un proceso investigativo construido, de automatización y de concientización del actuar (en todos los niveles de interacción social) en su historia, en sus prácticas cotidianas, en sus procesos de cambio y en sus consecuencias, es decir, la praxeología es entendida como un discurso (logos) construido después de una seria reflexión, sobre una práctica particular y significante (praxis), asimismo pensada como un procedimiento de objetivación de la acción y a su vez como una teoría de la acción; por el tipo de análisis que realiza pretende hacer que dicha praxis, en este caso la andragógica, sea más consciente de su lenguaje, de su funcionamiento y de lo que en ella está en juego, sobre todo del proceso social en el cual el actor o practicante está implicado y del proyecto de intervención que construye para cualificar dicho proceso; todo esto con el fin de acrecentar su pertinencia y su eficacia liberadora.

Así pues, se comprende a la praxeología como el resultado de un análisis empírico y de un discurso crítico, esta designa en primer lugar, una reflexión práctica sobre los principios de la acción humana y de sus técnicas, pero busca, igualmente, los principios generales y la metodología adecuada para una acción eficaz y pertinente.

En este sentido, la fundamentación teórica de la Andragogía establece una praxeología de carácter democrático por la horizontalidad de la interacción y la forma de participación basada en una relación de cooperación mutua de las partes integrantes en la actividad de aprendizaje, tal es el caso del facilitador y el participante.

Sin embargo, podría afirmarse que en la universidad venezolana la práctica docente se desarrolla aún bajo un enfoque tradicional; Gil (2005) señala que en la universidad venezolana la docencia todavía es sinónimo de «clase magistral», en la que un profesor (docto, se supone, por los viejos criterios heredados del medioevo y del positivismo decimonónico) «dicta» autárquicamente una serie de contenidos sin tomar en cuenta los intereses de sus estudiantes; todo lo contrario, hace énfasis en el cumplimiento de férreos programas y objetivos concebidos (a sus espaldas) para «agotar» temas y áreas del conocimiento.

Según el autor, entre el profesor y el estudiante se levanta una inmensa barrera que impide la verdadera interrelación y el crecimiento personal, aunado a eso señala que la evaluación de los aprendizajes es utilizada por el docente como un instrumento para ejercer el poder y la intimidación. Por otra parte, considera que el ambiente (aula) y el entorno universitario (campus) no son los más idóneos para el desarrollo de un proceso que debe estar signado por la flexibilidad, por la camaradería y por el compromiso académico, en pro de los objetivos comunes.

Es por ello que, las universidades en general y las venezolanas en particular, creadas como instituciones al servicio de la sociedad están llamadas a redefinir su praxis y 
redimensionarse a objeto de garantizar pertinencia social y científica en el trascender de la misma. La Universidad objeto de la presente investigación, y reconocida institución de naturaleza andragógica, no escapa de esta realidad, la misma fue creada en el año 1979 como una alternativa que diera respuesta a las exigencias de la educación superior en Venezuela, para ese momento. La UNESR plantea en sus basamentos filosóficos, enmarcar el proceso de aprendizaje bajo lo que definen como un Carácter Andragógico, ya que considera a sus estudiantes como una comunidad de gente adulta.

En relación a lo antes expuesto, es necesario profundizar en los fundamentos que cimientan dicha casa de estudios y a su vez en los constructos teóricos que sostienen las bases de una educación andragógica, con el propósito de conocer e interpretar la realidad y construir una aproximación teórica Trialéctica, que tome en consideración tres elementos imprescindibles del hombre; lo humano, lo cognitivo y lo social con el propósito de generar una Transformación Andragógica desde la Praxeología apoyada en la comunicación.

\section{Sendero Metodológico}

La perspectiva paradigmática estuvo orientada hacia un paradigma postpositivista con un enfoque cualitativo donde se privilegia la comprensión en profundidad del universo subjetivo humano, que nace de un modo de vivir, a través de la experiencia fenomenológica y hermenéutica, buscando el sentido y el significado dentro de la historicidad específica, interpretativa y comprensiva.

La investigación cualitativa, según Cerda (1999), se caracteriza por ser eminentemente humanista porque estudian a las personas desde un ángulo personal, que sienten y experimentan en las luchas cotidianas y se interesa por conocer lo que piensa la gente común. A razón de la facilidad de acceso y cercanía para las investigadoras, el escenario en el cual se realizó la investigación fenomenológica hermenéutica estuvo representado por los espacios de una Universidad pública en Venezuela. Los informantes clave para la aplicación de la metodología fenomenológica hermenéutica fueron un participante en formación y dos facilitadores de la misma universidad.

Para el desarrollo de esta investigación se utilizó como técnica para la recolección de la información la entrevista en profundidad, la cual se corresponden con el paradigma y el método seleccionado en razón del objeto de estudio, además es un medio empírico por excelencia que permite de una manera interrelacionarse dialógicamente en el contexto vital con los informantes clave que permita obtener información relevante vinculada con el propósito de la investigación.

En relación a la interpretación de los hallazgos de la investigación Martínez Miguélez (2008) señala que una vez recolectada la información, ésta debe pasar por un proceso de organización, lo que va a permitir encontrar sus significados. Por lo cual, es preciso resaltar que a este método le interesa responder cómo las personas dan sentido a su experiencia vivida en un contexto o frente a un fenómeno en particular. La finalidad es describir el significado de esa experiencia vivida frente a los fenómenos de interés, hacer visibles los rasgos de esa experiencia.

\section{Tratamiento de la información obtenida}


Para aplicar el método fenomenológico, Mendieta y otros (2015) plantean que el diseño metodológico implica la articulación de cuatro momentos: aplicar la epojé, un momento descriptivo en el que se analiza la intencionalidad y el — ser en el mundo—, la reducción, que se interpreta como el paso del momento descriptivo de la estructura fenoménica para lograr establecer patrones - la esencia - y la constitución que son los pasos objetivantes que se dan para construir el conocimiento. La presente investigación sigue esos momentos y la autora trabajó con las reducciones Fenomenológica, Eidética y Trascendental, que de acuerdo a Leal (1987) se definen de la siguiente manera:

La Reducción fenomenológica consiste en poner entre paréntesis, a modo de una suspensión de juicio, lo que Husserl denomina la actitud natural que es la creencia en la realidad del mundo, cuestionando de que, si lo percibido es real, supuestos teóricos que lo justifican, afirmaciones de las ciencias de la naturaleza, entre otros. Aquí solo debe quedar el residuo fenomenológico, a saber, las vivencias o fenómenos de la conciencia cuya estructura intencional presenta dos aspectos fundamentales: el contenido de conciencia, noema y el acto con que se expresa el contenido noesis.

La reducción Eidética: la ciencia de esta esencia, es la realidad fenomenológica, es la realidad fenoménica, por la libre consideración de todas las posibilidades que la razón descubre en ella, aquí pierde las características individuales y se revela una esencia constante e invariable. En esta reducción, la razón pone entre paréntesis todo lo del fenómeno, lo que constituye su esencia y su sentido o no, se va a la forma o su idea, intuición.

La reducción Transcendental, es el objetivo de la reducción fenomenológica, va más allá de solo la aparición de lo que se da en la conciencia, sino también, todo es conciencia, por la unicidad del noema y la noesis, que es representación de la conciencia, la subjetividad y sujeto que trasciende. A partir de la conciencia que trasciende, es el surgimiento de lo desconocido.

Hasta este momento se desarrolla el procedimiento fenomenológico, respetando los contenidos y esencias de cada informante; pero por tratarse de una investigación enmarcada en el método fenomenológico hermenéutico, corresponde además de ello realizar los Giros Hermenéuticos que vienen a representar el proceso intersubjetivo propiamente deconstructivo de la investigación, que consiste en establecer las verdades y premisas para el estudio.

En relación al Giro Hermenéutico Gadamer (1998), Derrida (1987), Habermas (1989) y Heidegger (1927), señalan, que el lenguaje es responsable del modo en que se aparecen los entes, por lo que queda establecido lo que una entidad es, por lo que lleva en sí la esencia del ser de los entes y la verdad de los mismos. Del mismo modo sostienen, que dentro de la línea hermenéutica existe una preeminencia del significado sobre la referencia. Al respecto, Gadamer (1984), señala que la designación de un objeto por un nombre no se da por una relación ostensiva directa, sino, por una relación indirecta en la cual los conceptos elaborados en el lenguaje sirven de nexo entre ambas partes, predominando de esa forma, su concepción holística. Este es una totalidad simbólica articulada donde cada parte adquiere su significado por referencia al todo; que son del todo ajenas a la corriente analítica. 


\section{Resultados}

Atendiendo la naturaleza del método fenomenológico-hermenéutico dicho procesamiento se describió en dos grandes etapas, es decir, en primer término, se presentan las reducciones: fenomenológica, eidética (de un informante) y trascendental (de todos los informantes) para luego a través de los giros hermenéuticos buscar la verdad de este estudio, mediante la desconstrucción de la realidad y posteriormente construir el postulado o fundamento teórico que tiene como propósito fundamental la investigación.

\section{Tabla 1.}

Reducción Fenomenológica. Informante Crítico

Investigador: ¿Qué sentido tiene para ti, la praxeología, entendida como aquel proceso de reflexión del actuar sobre una práctica particular, desde la gestión andragógica de esta institución?

\begin{tabular}{|c|c|}
\hline lógica & \\
\hline $\begin{array}{l}\text { Informante Crítico: listo, bueno Marieva fíjate que } \\
\text { cuando nosotros hablamos de la andragogía y puesto en } \\
\text { práctica desde el enfoque que tú le estás dando como la } \\
\text { praxeología, es hacer que el participante haga un proceso } \\
\text { metacognitivo, retrospectivo, que no se encasille en que } \\
\text { la andragogía es solamente la educación del adulto sino } \\
\text { que la andragogía trae implícito diferentes elementos bien } \\
\text { importantes en donde se asume el sujeto como un ser } \\
\text { pensante, capaz de criticar, capaz de cuestionar, capaz de } \\
\text { generar sus propios argumentos, en base a su experiencia } \\
\text { y a lo que la universidad le aporta como conocimiento } \\
\text { científico ¿no?; entonces, la realidad se ha visto ¿no? } \\
\text { Digamos que de unos años para acá distorsionada en esos } \\
\text { procesos ¿no? Porque hablamos de esos procesos } \\
\text { metacognitivos porque no dejamos a un lado lo que el } \\
\text { sujeto tiene pues, entonces, lo que yo tengo ¿Cómo lo uso } \\
\text { en mi realidad? ¿Cómo asumo yo ese proceso donde la } \\
\text { universidad me está diciendo debes replantearte un nuevo } \\
\text { enfoque de pensamiento? Tú tienes que reinventarte a } \\
\text { ravés de la teorética y tú tienes que } \\
\text { crear tus propias perspectivas y tu propia crítica } \\
\text { generando aportes significativos en la práctica facilitador- } \\
\text { participante, entonces ehhh estamos como en un proceso } \\
\text { apaciguado, estamos como que dejándonos arropar por lo } \\
\text { no }\end{array}$ & $\begin{array}{l}\text { Informante Crítico: cuando nosotros hablamos de la } \\
\text { andragogía y puesto en práctica desde el enfoque que tú } \\
\text { le estás dando como la praxeología, es hacer que el } \\
\text { participante haga un proceso metacognitivo, } \\
\text { retrospectivo, que no se encasille en que la andragogía } \\
\text { es solamente la educación del adulto sino que la } \\
\text { andragogía trae implícito diferentes elementos bien } \\
\text { importantes en donde se asume el sujeto como un ser } \\
\text { pensante, capaz de criticar, comunicarse, capaz de } \\
\text { cuestionar, capaz de generar sus propios argumentos, en } \\
\text { base a su experiencia y a lo que la universidad le aporta } \\
\text { como conocimiento científico ¿no?; entonces, la } \\
\text { realidad se ha visto ¿no? Digamos que de unos años } \\
\text { para acá distorsionada en esos procesos porque } \\
\text { hablamos de esos procesos metacognitivos porque no } \\
\text { dejamos a un lado lo que el sujeto tiene pues, entonces, } \\
\text { lo que yo tengo ¿Cómo lo uso en mi realidad? ¿Cómo } \\
\text { asumo yo ese proceso donde la universidad me está } \\
\text { diciendo debes replantearte un nuevo enfoque de } \\
\text { pensamiento? Tú tienes que reinventarte a través de la } \\
\text { teorética y tú tienes que crear tus propias perspectivas y } \\
\text { tu propia crítica generando aportes significativos en la } \\
\text { práctica facilitador-participante, entonces estamos } \\
\text { como en un proceso apaciguado, estamos como que } \\
\text { dejándonos arropar }\end{array}$ \\
\hline
\end{tabular}

Fuente: elaboración propia 
Tabla 2.

Reducción Eidética. Informante Crítico

Eidética

Proceso metacognitivo

Proceso retrospectivo

Se asume al sujeto como un ser pensante

Ser capaz de criticar

Ser capaz de cuestionar

Generar argumentos

la experiencia es relevante

la universidad es vista como una institución que aporta a sus conocimientos

Existe valoración de los conocimientos previos de la persona

Relaciona lo que se aprende en la institución con la realidad que vive en su cotidianidad

Exige plantearse nuevos enfoques de pensamiento

Promueve la construcción de nuevas perspectivas

Exige la generación de nuevos aportes al conocimiento, tanto del facilitador como del participante
Fenomenológica

Informante Crítico: listo, bueno Marieva fíjate que cuando nosotros hablamos de la andragogía y puesto en práctica desde el enfoque que tú le estás dando como la praxeología, es hacer que el participante haga un proceso metacognitivo, retrospectivo, que no se encasille en que la andragogía es solamente la educación del adulto sino que la andragogía trae implícito diferentes elementos bien importantes en donde se asume el sujeto como un ser pensante, capaz de criticar, capaz de cuestionar, capaz de generar sus propios argumentos, en base a su experiencia y a lo que la universidad le aporta como conocimiento científico ¿no?; entonces, la realidad se ha visto ¿no? Digamos que de unos años para acá distorsionada en esos procesos ¿no? Porque hablamos de esos procesos metacognitivos porque no dejamos a un lado lo que el sujeto tiene pues, entonces, lo que yo tengo ¿Cómo lo uso en mi realidad? ¿Cómo asumo yo ese proceso donde la universidad me está diciendo debes replantearte un nuevo enfoque de pensamiento? Tú tienes que reinventarte a través de la teorética y tú tienes que crear tus propias perspectivas y tu propia crítica generando aportes significativos en la práctica facilitador-participante, entonces ehhh estamos como en un proceso apaciguado, estamos como que dejándonos arropar por lo no andragógico, a pesar que la universidad desde el momento que asume que el participante ingresa con dieciséis,

Fuente: elaboración propia 
Tabla 3.

Reducción trascendental: El sentido que se le otorga a la praxeología desde la gestión andragógica

Crítico

La praxeología es vista como un proceso metacognitivo y retrospectivo en el cual el adulto es concebido como un individuo pensante; que puede ser capaz de cuestionar, de criticar, de generar argumentos propios en torno a algo, un proceso en el que la experiencia de ese ser representa un aporte significativo al conocimiento, rescatando la valoración que tienen los conocimientos previos de la persona. Por otra parte, favorece la relación entre lo que se aprende con la realidad de cada ente y a partir de allí se pueden generar nuevos aportes al conocimiento.

Dentro de este constructo, la universidad no está representada como una institución dadora de clases sino como un espacio de participación activa de todos los actores

\section{Empatía}

Es considerada como un acto de total reflexión que va a favorecer cambios significativos en la persona y su entorno, asimismo valora la importancia que tiene este proceso desde la gestión andragógica pues toma en cuenta los conocimientos previos que tiene el adulto y se enriquecen con los nuevos aportes que se generan dentro de la institución; hecho que permite desarrollar un proceso introspectivo desde los ambientes académicos hacia las realidades.

De igual manera se concibe como un espacio de apertura al cambio en el que se sostiene el firme reconocimiento de que no hay una sola verdad, entendiendo que entre todos se construyen los nuevos aprendizajes por medio del intercambio de experiencias.
Entusiasta

Va más allá de los contenidos teóricos, trasciende de manera significativa en las experiencias vividas. Admite relacionar los saberes anteriores con las vivencias y así con el apoyo de la teorética facilitar la manera en que se aprende.

Favorece la reflexión, el actuar con madurez, se logra comprender que los saberes deben llevarse a la práctica; y se asumen las fallas como una experiencia de la que se puede obtener un aprendizaje; la reflexividad eleva el nivel de conciencia, partiendo del reconocimiento de que siempre se puede mejorar y que el estar preparado propicia la transmisión y multiplicación de los saberes, con el irrebatible propósito de ser una mejor persona.

Fuente: elaboración propia 
Tabla 4.

Reducción trascendental: El significado que le da a la praxeología andragógica desde el punto de vista humano, cognitivo y social

\begin{tabular}{|c|c|c|}
\hline Crítico & Empatía & Entusiasta \\
\hline $\begin{array}{l}\text { La praxeología andragógica desde } \\
\text { lo humano, asume a la persona } \\
\text { como un ser biopsicosocial; que } \\
\text { debe mantenerse en un estado } \\
\text { equilibrado en esos tres elementos } \\
\text { para que su conducta operante sea } \\
\text { asertiva. }\end{array}$ & $\begin{array}{l}\text { Desde el punto de vista humano es } \\
\text { considerada como un compromiso } \\
\text { de todos los actores involucrados, } \\
\text { en el que debe privar el respeto a } \\
\text { los procesos y a su postura como } \\
\text { adulto. } \\
\text { Donde la universidad y el }\end{array}$ & $\begin{array}{l}\text { Destaca una especial relación de las } \\
\text { vivencias con los constructos } \\
\text { teóricos desarrollados, lo que le } \\
\text { otorga al conocimiento el camino } \\
\text { para trascender como persona, } \\
\text { mejorando su condición de ser } \\
\text { humano y de ciudadano inmerso en } \\
\text { una sociedad. }\end{array}$ \\
\hline $\begin{array}{l}\text { En relación con el abordaje } \\
\text { cognitivo esta práctica andragógica } \\
\text { permite identificar las necesidades } \\
\text { cognoscitivas del adulto para, a } \\
\text { partir de allí desarrollar los } \\
\text { contenidos teóricos - conceptuales, } \\
\text { a su vez favorece la contrastación } \\
\text { de la formación epistémica con la } \\
\text { vida cotidiana. }\end{array}$ & $\begin{array}{l}\text { conocimiento deben fusionarse, } \\
\text { caminar unidos y no separados; le } \\
\text { otorga importancia a llevar a la } \\
\text { práctica los nuevos saberes desde } \\
\text { una comunicación acertiva, ya que } \\
\text { el desarrollo del nuevo } \\
\text { conocimiento depende de la } \\
\text { combinación que se haga de la } \\
\text { teorética-práctica-experiencia }\end{array}$ & $\begin{array}{l}\text { Dicha praxeología permite la toma } \\
\text { de conciencia de las acciones y una } \\
\text { comunicación adecuada, elementos } \\
\text { indispensables para evolucionar. }\end{array}$ \\
\hline
\end{tabular}

Fuente: elaboración propia

\section{Quiebre Hermenéutico desde una Filosofía Fenomenológica}

A continuación se presenta una fase considerablemente relevante en el camino a la comprensión en busca de la verdad, con la intención de descubrir la realidad desde la experiencia vivida de los entrevistados; como lo señala Gadamer (1998), "consiste en ir más allá de lo presente" p. (70), dicho de otro modo, se trata de traspasar esa cortina y lograr develar la esencia implícita en la misma.

Ahora bien, es interesante destacar el planteamiento de Martin Heidegger con relación a este proceso; León (2009) señala que para Heidegger el fenómeno del que se ocupa primeramente la fenomenología, está oculto, encubierto, obstruido. Y ese fenómeno no es otro que el ser, y es ocultado o encubierto por todos los demás fenómenos que acaparan nuestra atención de un modo inmediato.

Para sacar a la luz el sentido del ser, continúa León (2009), es necesario partir de la caracterización del ser, en tanto que abierto a la comprensión del ser, apertura que Heidegger designa como posibilidad de ser o proyecto libre.

Con el fin de continuar el proceso deconstructivo de la realidad, se procede a establecer las verdades y premisas para este estudio, las cuales orientan al Giro Hermenéutico en la búsqueda de la argumentación con las posturas teóricas de investigadores relacionados con el abordaje de la temática de este estudio. 


\section{Naturaleza reflexiva del Ser}

A la luz de la Verdad: Los procesos de aprendizaje que se encuentran bajo un esquema formal se configuran jerárquicamente a partir de la edad y el desarrollo evolutivo del individuo, en el caso particular de las personas en edad adulta se requiere de una metodología adaptada a sus necesidades e intereses; en relación a ello, la verdad para esta persona, es que se asume el sujeto como un ser pensante, capaz de criticar, capaz de cuestionar, capaz de generar sus propios argumentos, todo esto en base a su experiencia. Desde la andragogía se reconoce el hecho de que el sujeto debe pasar por un proceso de cuestionamiento y reflexión total y consciente de sus acciones, considerando que esto solo se logra a través de la indagación profunda de las cosas.

De igual manera, sobre la misma dinámica reflexiva se transcurre por un proceso de reconocimiento personal y de los otros, que va permitir el intercambio de pensamientos enmarcado en el respeto, con el fin de generar nuevos aportes al conocimiento, desde todos y para todos.

A la luz de la Teoría: los siguientes señalamientos son parte de un trabajo desarrollado por Policarpo Chacón y Melchor Aguilar (2017), que da cuenta que el pensamiento reflexivo es un proceso que no puede generarse de manera aislada de otros procesos como la transformación de la conciencia y la generación de pensamientos. Para estos autores, la reflexión es la facultad de conocer, de hacerse consciente de algo; entonces, en los procesos educativos o de formación, es importante pensar lo que va a hacerse, hacer consciente la acción; aunque cuando se habla de conciencia, no significa que todo se resuelva, al menos en lo que respecta al proceso educativo, porque, como advierte Rousseau (2007): “Cuando más uno reflexiona, más dificultades nuevas se le presentan" (p. 15).

Ahora bien, si se considera que, a través de la reflexión es cómo se llega a la verdadera naturaleza de las cosas, entonces, el pensamiento reflexivo es la actividad propia de cada sujeto, es un proceso íntimo que se revela en la conciencia, lo cual significa que nadie puede pensar por otro; además, por medio de la reflexión es como los sujetos transforman su conciencia, pues como ya se mencionó, ella es la que transforma los sentimientos o las representaciones en pensamientos.

\section{Valoración de la experiencia como base del aprendizaje}

A la luz de la Verdad: Reconocer que la experiencia del sujeto adulto es la base fundamental que servirá de piso para la construcción de los nuevos aprendizajes, es una de las formas de expresión de esta persona para manifestar desde su verdad que el docente debe entender que el estudiante adulto aprende a través de sus experiencias, que su conocimiento no lo va a construir solamente con lo teórico sino a través de la práctica, así como también con las vivencias que trae de sus conocimientos anteriores, para esta persona la experiencia social y la cognitiva es clave, porque según ella, ubica al estudiante en el contexto y la realidad. A su vez manifiesta que el proceso de aprendizaje se puede nutrir a través del intercambio de experiencias.

A la luz de la Teoría: la Teoría del Aprendizaje Experiencial, según Gómez (2012) se centra en la importancia del papel que juega la experiencia en el proceso de aprendizaje. Desde 
esta perspectiva, el aprendizaje es el proceso por medio del cual se construye conocimiento mediante un proceso de reflexión y de "dar sentido" a las experiencias.

\section{Exaltación de los conocimientos previos}

A la luz de la Verdad: Desde el punto de vista de esta persona, la información que el estudiante adulto trae consigo juega un papel esencial en el desarrollo de su proceso de aprehensión del conocimiento nuevo; considera este aspecto dentro del hecho andragógico como un proceso de transformación que se da en el sujeto; a partir de la sinergia entre la información previa y la información desarrollada durante su formación académica, lo que va a hacer posible que se genere un proceso de reflexión desde los espacios académicos hacia las realidades de cada uno de los actores involucrados.

A la luz de la Teoría: Rivero (2017) destaca que el adulto es un ser en situación, no en expectativa, sea cual sea su nivel académico es responsable de un proyecto de vida en el presente, por lo cual, el aprendizaje para él supone una actividad secundaria, no obstante, es un proceso que se encuentra paralelo a otras actividades relacionadas con su vida personal, familiar, social o laboral. Asiste de forma voluntaria a las diversas actividades académicas.

De esta manera, las capacidades y actitudes del adulto para aprender están más relacionadas con el ejercicio y la práctica que con la edad. Son personas acostumbradas a asumir las responsabilidades de sus acciones y cuentan con una valiosa experiencia previa que se convierte en enriquecedora del proceso de aprendizaje. Como adultos, viven en un período de cambio marcado por etapas en las cuales, se experimentan transformaciones relacionadas con aspectos como el rol social, el autoconcepto, la educación o la motivación.

\section{La Universidad como espacio de participación activa y comunicativa}

A la luz de la Verdad: Dentro de la dinámica andragógica, para este individuo, la universidad no está representada como una institución dadora de clases sino como un espacio de participación activa de todos los actores protagonistas del proceso de aprendizaje, en la cual el quehacer universitario es diferente; donde los nuevos aprendizajes se construyen con la participación de todos en un clima de comunicación acorde con el nivel, ya que en este espacio no existe una verdad absoluta; sino que se manejan diferentes campos de verdad, que al ser nutridos con las experiencias y la profundización teórica de facilitador y participantes va a permitir la ampliación de la información que se tiene y los argumentos para posicionarse en las diferentes teorías que conforman el vasto campo del conocimiento.

A la luz de la Teoría: El aula universitaria se concibe, según Gómez y Prado (2015) como un espacio multicultural donde las interacciones humanas que surgen de la praxis andragógica llevan a descubrir en los actores principales: participante y facilitador un rol activo, con una visión dialógica donde se distinguen dos principios de la acción andragógica: la horizontalidad y la participación.

Estos principios se encargan de estructurar las relaciones comunicativas entre los actores, hecho fundamental para la construcción de saberes. En ese sentido, Adam (1987) señala que la 
praxis andragógica fundamentada en los principios de participación y horizontalidad; incrementa el pensamiento crítico, la autogestión del aprendizaje, la participación activa, la calidad de vida y la creatividad del participante adulto, proporcionado una oportunidad para lograr su autorrealización.

Por lo antes planteado, se expresa que la praxis andragógica en la cosmovisión del aula universitaria proporciona al adulto la posibilidad de participar activamente en la planificación de su aprendizaje en condiciones de igualdad, tanto con sus compañeros como con el facilitador teniendo en cuenta los principios que acompañan a la praxis andragógica (horizontalidad y participación); todo ello conjuntamente con un aula multicultural.

En este orden de ideas, surge la Trama Trialéctica para la Transformación Andragógica desde la educación Universitaria Fundamentada en la Praxeología. Una Construcción Teórica desde la Acción Comunicativa - Reflexión Del Ser que se presenta a continuación:

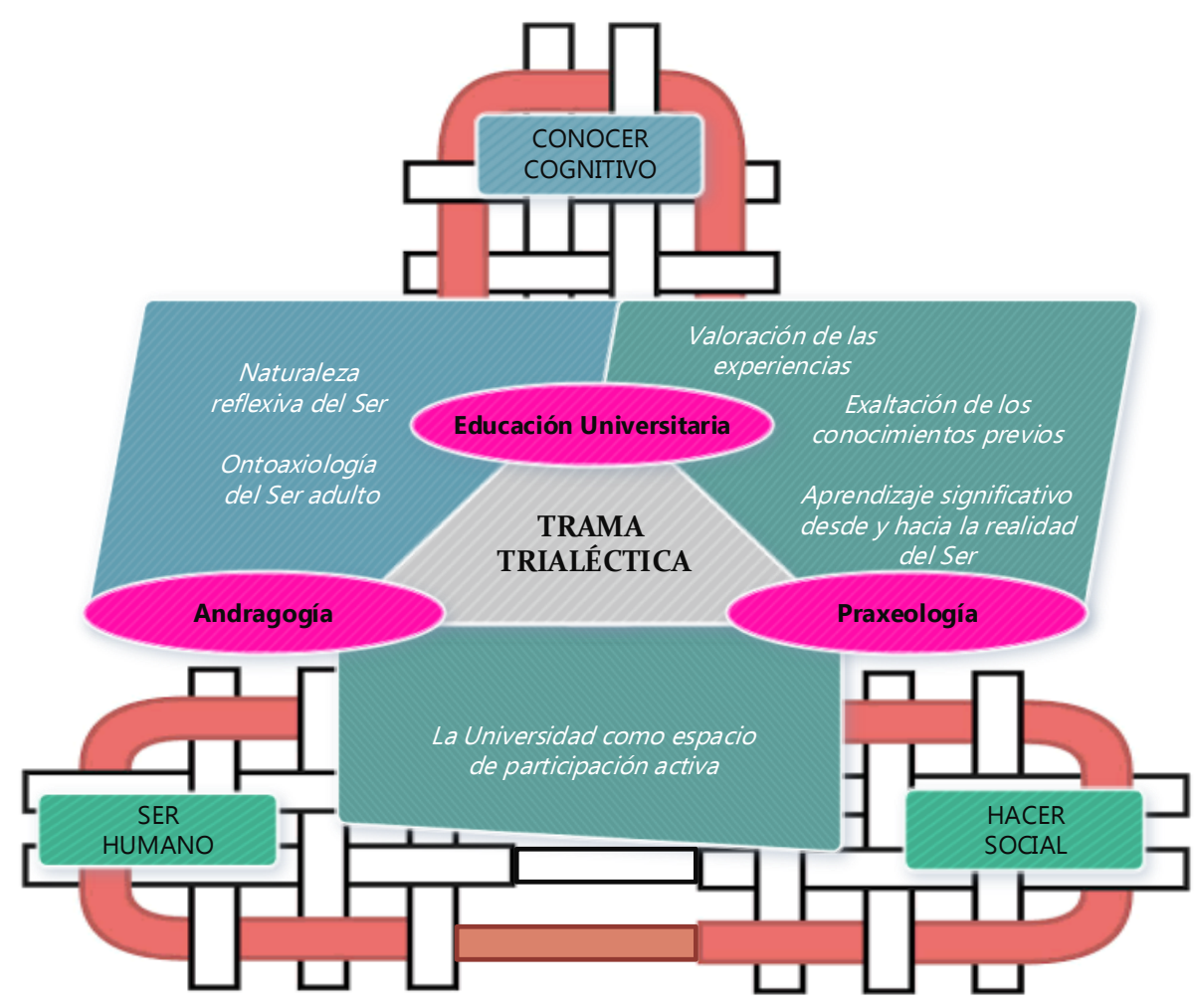

Figura 1. Trama Trialéctica para la Transformación Andragógica desde la educación Universitaria Fundamentada en la Praxeología. Una Construcción Teórica desde la Acción Comunicativa - Reflexión Del Ser.

La educación universitaria venezolana en la actualidad pide mecanismos de transformación que permitan el avance de sus miembros, lo que se verá reflejado en la evolución de la sociedad; estos mecanismos deben considerar todos los elementos que configuran al Ser desde toda su óntica; sin embargo, existen instituciones de educación superior en las que se continúa atesorando en sus procesos educativos el desarrollo del aprendizaje cognitivo, por encima de los demás aspectos que también son inherentes a la persona. Es necesario entonces, 
valorar al hombre en su totalidad, reconocer que ante todo es un ser biológico, en un cuerpo físico y mente, además de ello se desenvuelve en un espacio determinado y a su vez viene cargado de una historia personal, todo ello debe considerarse al momento de construir cualquier metodología educativa de enseñanza.

La figura anterior, detalla lo que es el resultado de este proceso de construcción de conocimiento nuevo; que la autora denomina Trama Trialéctica; a razón de que la palabra trama tiene su génesis en un vocablo latino que hace referencia al grupo de hilos que combinados y enlazados junto a los de la urdimbre consigue darle forma a una tela.

\section{Tabla 5}

Fundamentación Filosófica de la Trama Trialéctica para la Transformación Universitaria

\begin{tabular}{ll}
\hline Fundamentos & Trama Trialéctica \\
\hline La Trama Trialéctica presentada se fundamenta en el abordaje \\
andragógico de los estudios de educación universitaria con el \\
agregado especial que le aportan los postulados de la Praxeología, \\
como un mecanismo de reflexión y acción de la labor del \\
participante adulto dentro y fuera de los espacios de aprendizaje, \\
asimismo implica un esfuerzo comprometido para profundizar en \\
esos postulados por parte del docente con el propósito de \\
desarrollar su práctica educativa en correspondencia con los \\
mismos. Ahora bien, todo proceso de transformación a nivel \\
educativo implica una posición epistemológica a partir de la cual \\
se plantea el ser, conocer y hacer producto del proceso de \\
aprendizaje. El centro de atención será siempre el ser humano, \\
donde sus necesidades e intereses sean la base desde donde se \\
construirá su formación académica y se desarrollará su \\
personalidad, así como también abogará por el pleno y libre \\
desenvolvimiento de sus acciones individuales y su interacción con \\
sus pares y el entorno en el que se desenvuelve, donde no sólo se \\
considere el proceso académico del aprendiz como tal, sino que \\
también se construya una acción que exige de todos los actores \\
involucrados en el proceso para así promover una nueva visión de \\
las creencias, del quehacer institucional, del desempeño docente y \\
de la función educativa y social que se promueve.
\end{tabular}

Fuente: elaboración propia 


\section{Tabla 6}

\section{Fundamentación Ontológica y Gnoseológica}

\begin{tabular}{ll}
\hline Fundamentos & Trama Trialéctica \\
& Se plantea el desarrollo de un ser reflexivo, praxeológico, que \\
realice el proceso de introspección antes, durante y después de su \\
actuar, en el que se preste especial atención y se validen sus \\
conocimientos previos; así como también se promueva el \\
desarrollo de sus experiencias dentro del ámbito de formación, \\
favoreciendo la relación entre los miembros participantes del acto \\
educativo andragógico. \\
Tomando en cuenta que una persona adulta se encuentra en la \\
plena capacidad de cuestionar, criticar y argumentar posturas en \\
torno a los diferentes aportes y teorías del conocimiento, así como \\
también tomar decisiones sobre su formación académica, que \\
concibe a la universidad como una institución al servicio de la \\
persona y de la sociedad. \\
Concibe la construcción del conocimiento como una actividad \\
individual, así como también de interacción colectiva, dando \\
especial importancia para el efectivo desarrollo del mismo a los \\
saberes previos y la experiencia. La fundamentación praxeológica \\
del conocimiento se da, en el sentido de las acciones, en otras \\
palabras, la práctica de; pero no en una práctica tradicional sino en \\
una práctica reflexiva, que permita visualizar que ante una realidad \\
dinámica e inacabada cultivar el acto reflexivo va a permitir \\
aprender y desaprender libremente, aceptar que hay cambios, nutrir \\
las vivencias y comprender que no hay fin, sino transitoriedad. \\
Fnoseológico
\end{tabular}

Fuente: elaboración propia 


\begin{tabular}{l} 
Tabla 7 \\
Fundamentación Axiológico y Teleológico \\
\begin{tabular}{c} 
Trama Trialéctica \\
\hline Fundamentos
\end{tabular} \\
$\begin{array}{c}\text { Normalmente se le atribuye a la educación bajo una orientación } \\
\text { andragógica la presencia de ciertos principios y/o valores tales } \\
\text { como: la horizontalidad; que permite la interacción (sujeto } \\
\text { facilitador - sujeto participante del proceso educativo) en igualdad } \\
\text { de condiciones; asimismo promueve la participación, invitando al } \\
\text { desarrollo de un espacio de colaboración y aportación al proceso } \\
\text { de aprendizaje de todos los protagonistas de proceso educativo y, } \\
\text { que ésta a su vez sea abierta; y la flexibilidad como mecanismo de } \\
\text { apertura del proceso de formación rompiendo con los viejos } \\
\text { paradigmas que mantienen al aprendizaje como un proceso rígido. } \\
\text { De la misma manera, desde esta trama trialéctica se proponen } \\
\text { nuevos valores que surgen de los protagonistas del estudio } \\
\text { previamente presentado; como lo son compromiso, igualdad, } \\
\text { empatía, responsabilidad y respeto. } \\
\text { Atendiendo a la realidad de que el Ser Humano, es un ser } \\
\text { biológico, psicológico y comunicativo, esta Trama tiene como } \\
\text { finalidad promover una educación que transite más allá del solo } \\
\text { proceso de formar cognitivamente a la persona. Desde la misma se } \\
\text { trata de ampliar la mirada, de abordar los procesos formativos } \\
\text { desde una conciencia global reflexiva, atender y validar las } \\
\text { necesidades de la persona, propiciar el desarrollo de las } \\
\text { habilidades mentales requirentes para su proceso de formación } \\
\text { integral, así como también establecer espacios de participación } \\
\text { activa, de interacción, de vinculación con sus pares. }\end{array}$ \\
Fuente: elaboración propia \\
\hline Teleológico
\end{tabular}

\section{Conclusiones}

En el caso particular de este estudio, la Trama Trialéctica que surge de la presente investigación se dimensiona en base a tres elementos relevantes dentro del proceso formativo del ser humano, tal y como se presenta en la figura anterior.

Educación Universitaria, es propuesta como una educación que promueve la valoración de las experiencias del adulto; donde la misma es vista como un proceso de experimentaciónacción y/o como una forma de acercamiento del individuo a los contextos de aprendizaje a través de su práctica comunicativa asertiva, permitiendo así que este tenga la capacidad de discernir sobre el nuevo conocimiento luego que supere la experiencia concreta y logre reflexionar sobre ella; a su vez es una educación que exalta los conocimientos previos, entendiendo que un adulto en situación de aprendizaje tiene plena conciencia sobre lo que puede aportar a su proceso; por la carga cognitiva, afectiva, cultural, social, entre otras; en la que está envuelto, logrando así que el aprendizaje adquirido sea significativo y que se manifieste desde y hacia su realidad, impactando favorablemente la sociedad en la cual este se desenvuelve. Desarrollo pleno del Conocer Cognitivo.

Praxeología, promueve en la persona adulta la capacidad de reflexionar sobre sus prácticas, sean estas individuales o colectivas, se plantea como un ejercicio de autoobservación profunda antes, durante y después de llevar a cabo sus acciones, fomentando las habilidades de pensamiento, cuestionamiento, crítica, autocrítica, introspección, que le permitan apropiarse de 
nuevos saberes, así como también soltar los saberes expirados. Por otra parte, propone a la institución universitaria como un espacio de participación activa que va a propiciar la interacción social de los miembros del quehacer educativo con el fin de lograr construir nuevas experiencias en pro del colectivo. Desarrollo pleno del Hacer Social.

Andragogía, plantea el impulso de una educación enfocada en el desarrollo del SER, considerando y respetando su condición bio-psico-social de adultez, asumiéndolo como un individuo maduro, capaz de tomar decisiones y acciones reflexivas en búsqueda de su formación integral; en otras palabras, se exorta que el proceso de aprendizaje se encuentre centrado en la persona; donde se valoren los intereses y necesidades reales del educando, se promueva el desarrollo de su naturaleza reflexiva, además de ello que el rol que cumpla el docente (también adulto) sea de acompañamiento del proceso y que el ambiente donde este se dé sea un espacio de empatía, autonomía, libertad, cooperación, respeto y responsabilidad. Desarrollo pleno del Ser Humano.

La sociedad requiere de seres completamente comprometidos con el mejoramiento de los espacios comunitarios, académicos, empresariales, educativos, organizacionales, entre otros; el SER que debe estar por encima de todo, pues es parte del todo y sin él nada evolucionaría tiene la responsabilidad de elevar su nivel de conciencia; ampliar su horizonte perceptivo, desarrollar dominio propio, reflexividad, empatía, debe educarse en el manejo de sus emociones, debe posicionarse desde lo humano en cualquier actividad que desee realizar, respetando al otro.

\section{Bibliografía}

Alcalá, A. (2010). Propuesta de una definición unificadora de la Andragogía. Trabajo no publicado. Caracas: Universidad Nacional Abierta.

Caraballo, R. (2007). La Andragogía en la Educación Superior. Investigación y Postgrado UPEL, 22 (2) ,187-206.

Cerda, H. (1999). Los elementos de la investigación. Santa fe de Bogotá: Ediciones El Búho.

Derrida, J. (1987). La desconstrucción en las fronteras de la filosofía. La retirada de la metáfora. Barcelona, España: Ediciones Paidós Iberia, S. A.

Gadamer, H. (1984). Verdad y Método: fundamentos de una hermenéutica filosófica. Salamanca: Ediciones Sígueme.

Gadamer, H. (1998). El Giro Hermenéutico. Madrid: Ediciones Cátedra.

Gil, R. (2005). La sociedad transcompleja y la praxis andragógica en la educación superior. FERMENTUM 15(43), 276-287

Gómez, G. (2012). Habilidades sociales. México: Ediciones Universidad Autónoma de México.

Gómez, P. y Prado, Y. (2015). Modelo andragógico para el aprendizaje significativo de la investigación educativa. REDHECS $\square$ Revista en línea $\square$. Volumen 19 Edición No 19 Año 10 Abril - Septiembre 2015. Recuperado de file:///C:/Users/MariaE/Downloads/2475Texto\%20del\%20art\%C3\%ADculo-5231-1-10-20180502.pdf $\square$ Consultado, miércoles 9 de enero de $2019 \square$.

Habermas, J. (1989). El discurso filosófico de la modernidad, Madrid: Ediciones Taurus Heidegger, M (1927). El Ser y El Tiempo. México: Ediciones Fondo de Cultura Económica.

Leal, N. (1987). El Mundo del estudiante, UNA. (Aportes para la comprensión del marco fenoménico del estudiante a distancia sus percepciones, expectativas y dificultades).

Esta obra se comparte bajo la licencia Creative Common Atribución-No Comercial 4.0 International (CC BY-NC 4.0) Revista de la Universidad Internacional del Ecuador. URL: https://www.uide.edu.ec/ 
Ponencia presentada en la jornada de asesores y especialista en contenido del área de estudios generales a nivel nacional. UNA. San Antonio de los Altos.

León, E. (2009). El giro hermenéutico de la fenomenológica en Martin Heidegger. Polis $\square$ Documento en línea. Recuperado de http://journals.openedition.org/polis/2690 $\square$ Consultado, miércoles 9 de enero de 2019 .

Martínez Miguélez, M. (2008). La ciencia y Arte de la Investigación Cualitativa. México: Ediciones Trillas.

Mendieta-Izquierdo G, Ramírez-Rodríguez JC, Fuerte JA. (2015). La fenomenología desde la perspectiva hermenéutica de Heidegger: una propuesta metodológica para la salud pública. Rev. Fac. Nac. Salud Pública 2015; 33(3): 435-443. DOI: 10.17533/udea.rfnsp.v33n3a14

Policarpo Chacón, A y Melchor Aguilar, J. (2017). La formación de sujetos reflexivos. Revista de Educación y Desarrollo, 40. Enero-marzo de 2017. Recuperado de http://www.cucs.udg.mx/revistas/edu_desarrollo/anteriores/40/40_Chacon.pdf

$\square$ Consultado, viernes 11 de enero de 2019.

Rousseau, J (2007). Emilio o, de la Educación. Madrid: Ediciones Alianza

ST-Arnaud, Y. - L'Hotellier, A. (1992). Connaître par l'action. Montreal: Presses de 1'Universite de Montreal. 